\title{
The epidemiology of hepatitis C in a UK health regional population of 5.12 million
}

\author{
A H Mohsen, Trent HCV Study Group
}

\begin{abstract}
Background-The epidemiology and natural history of hepatitis $\mathrm{C}$ virus (HCV) infection in the UK are uncertain. Previous reports are from small or selected populations such as blood donors or tertiary referral centres.
\end{abstract}

Aims-To study the epidemiology and natural history of $\mathrm{HCV}$ infection.

Methods-Prospective study incorporating five centres within the Trent region. Patients were managed and followed up according to a commonly agreed protocol. Subjects-A total of $1128 \mathrm{HCV}$ positive patients. Patients with haemophilia, human immunodeficiency virus, and chronic renal failure were excluded.

Results-Between September 1991 and December 1998, 2546 anti-HCV positive patients were identified of whom 1128 (44\%) were enrolled in the cohort. A risk factor(s) for infection was identified in $93.4 \%$ of patients who completed the questionnaire; $81 \%$ of patients were HCV RNA positive. A total of 397 initial liver biopsies were scored by a single pathologist. These showed a correlation between high alcohol intake and fibrosis score. Multivariate analysis showed fibrosis to be associated with age over 40 , past evidence of hepatitis $B$ virus infection, and higher necroinflammatory grade but not with sex, viral genotype, maximum known alcohol intake, estimated duration of infection, or mode of transmission. Twelve $(7.8 \%)$ of 153 patients who received interferon therapy had sustained serum virus clearance. Sixty six patients have died during the follow up period, 31 with a liver related cause of death. This represents a considerable excess over the expected death rate for a cohort of this age and sex distribution.

Conclusions-HCV infection is an emerging health problem in the Trent region. Identifying risk factors for infection and disease severity will enhance understanding and facilitate improved intervention. An excess mortality in infected individuals is already evident in this unselected cohort.

(Gut 2001;48:707-713)

Keywords: hepatitis C; epidemiology

Dr M W McKendrick,

Department of Infection and

Tropical Medicine, Royal

Hallamshire Hospital,

Sheffield S10 2JF, UK

mike.mckendrick@csuh.nhs.uk

Accepted for publication

14 November 2000
Hepatitis C virus (HCV) was first described in 1989. With the increasing use of antibody testing, the recognised prevalence of infection has increased and an estimated $21 \%$ of community acquired acute viral hepatitis is now reported to be due to $\mathrm{HCV}^{2}$ Acute infection is usually clinically silent ${ }^{3}$ but $\mathrm{HCV}$ is now recognised as one of the leading causes of chronic liver disease. Up to 3\% of the world's population may be infected, equating to 170 million chronic HCV carriers worldwide. ${ }^{4}$ There is considerable variation in seroprevalence. ${ }^{4}$ Values of $>10 \%$ are reported from Egypt for example ${ }^{5}$ while in the UK estimates of $\mathrm{HCV}$ antibody positive rates vary from $0.08 \%$ to $0.72 \% .^{6-8} \mathrm{Up}$ to $90 \%$ of $\mathrm{HCV}$ carriers may progress to chronic liver disease $^{9}$ and $20-30 \%$ of these will probably progress to cirrhosis and its complications. ${ }^{10} 11$ Recent evidence suggests that $\mathrm{HCV}$ infection is a major factor in the recent increase and age reduction of hepatocellular carcinoma in the USA. ${ }^{12}$ In most countries where data are available, HCV infection is the leading cause of liver transplantation. $^{13}$

Trent region is an administrative health area in eastern central England with a population of about 5.12 million. Following the introduction of HCV antibody screening of donated blood (September 1991), the Trent Centre of the National Blood Authority (NBA) arranged referral of antibody positive donors to one of seven clinics. Detailed epidemiological data from these donors were collected on a central database. Subsequently, identical data were collected from any antibody positive patient referred to the regional centres from other sources and the database has expanded to include laboratory data. The Trent HCV Study Group was established in 1991 as a collaborative multidisciplinary effort (with expertise in infectious diseases, gastroenterology, pathology, epidemiology, blood transfusion, and clinical and molecular virology) with the objective of studying the epidemiology and natural history of HCV infection and facilitating research into the pathogenesis of $\mathrm{HCV}$ associated disease. This paper describes the epidemiology of HCV infection in Trent.

\section{Methods}

LABORATORY AND CLINICAL DATA

The total number of anti-HCV positive patients in the Trent region was determined by requesting data on all samples found to be anti-HCV positive from the diagnostic laboratories serving the region. The minimal

Abbreviations used in this paper: $\mathrm{HCV}$, hepatitis $\mathrm{C}$ virus; $\mathrm{HBV}$, hepatitis $\mathrm{B}$ virus; RT-PCR, reverse transcriptase-polymerase chain reaction; IDU, injecting drug user; HIV, human immunodeficiency virus; anti-HBc, antibody to hepatitis B core antigen; HBsAg, hepatitis B surface antigen; NBA, National Blood Authority. 
identifier/demographic data available were the date of blood sample, date of birth, sex, and source of test request (for example, hospital physician, general practitioner, genitourinary medicine clinic).

The diagnostic antibody tests used have changed over time and with centre. Anti-HCV was determined in serum samples using second and third generation enzyme linked immunosorbent assays and confirmed by standard protocols in place at the time. The presence of HCV RNA in serum samples was measured originally using an inhouse nested reverse transcriptase-polymerase chain reaction (RTPCR) assay ${ }^{14}$ and since 1995 by a commercially available RT-PCR kit (Amplicor; Roche Diagnostics, East Sussex, UK). RT-PCR positive samples were genotyped by restriction fragment length polymorphism assay. ${ }^{15}$

THE TRENT HCV STUDY COHORT

All patients referred to one of the participating clinics with a diagnosis of $\mathrm{HCV}$ infection were invited to enrol in the cohort study, with informed consent. A detailed epidemiological questionnaire was administered by interview with trained personnel. The questionnaire was designed to identify an extensive range of factors likely to result in the spread of blood borne viruses. It encompassed basic demographic data as well as information on injecting (intravenous) drug use (IDU), exposure to blood products, tattooing, and other activities with needles such as body piercing, health care work, and family risks. ${ }^{16}$ Alcohol consumption was recorded at initial consultation (history of heavy alcohol consumption, defined as $>50$ units per week for most weeks over a period of six months, and average weekly consumption at the time of initial questionnaire) and then prospectively by documenting the average weekly alcohol intake since the previous clinic visit. For the purpose of analysis of alcohol as a risk factor, the highest known alcohol intake for an individual patient was used.

Patients with haemophilia, known human immunodeficiency virus (HIV) infection, or undergoing renal replacement therapy were not routinely enrolled in the cohort study, as the natural history of infection may differ in these patient groups.

All patients were managed according to a regionally agreed clinical management protocol (fig 1). Treatment was interferon based, usually 3 megaunits three times weekly for six months initially, the period of treatment extending to 12 months in the latter period of the study (it was not the intention of this study to formally evaluate therapeutic response in a controlled manner). Liver biopsies were scored for necroinflammatory grade $0-18$ and fibrosis stage 0-4 using the Knodell system. ${ }^{17}$ Assessment of liver biopsies for the study was performed by a single pathologist (JCEU) blinded to all data other than patient identifiers.

Multicentre and local research ethics committee approval was obtained for the study. The data were made anonymous and stored on a Microsoft Access database. The $\chi^{2}$ test was

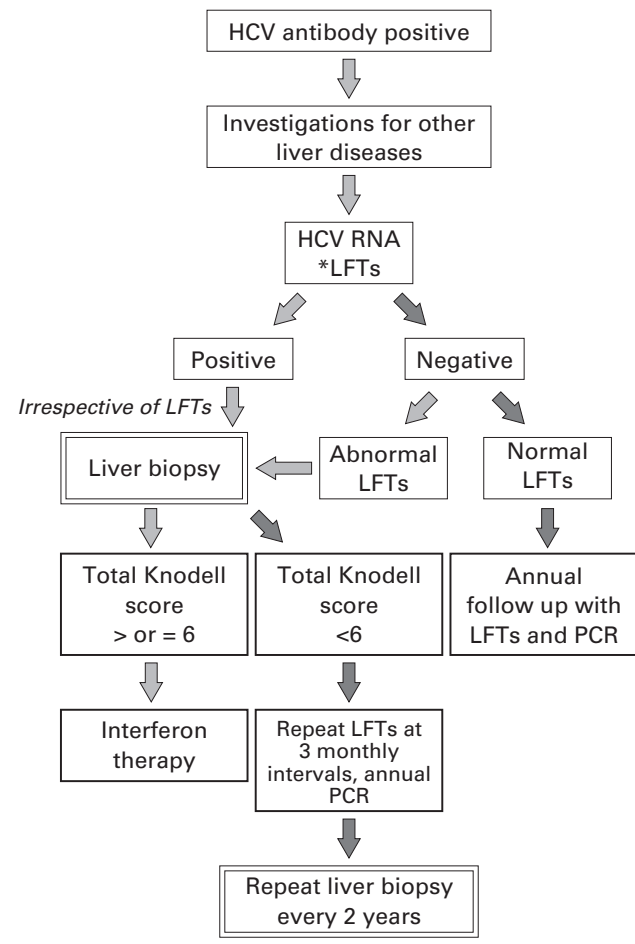

Figure 1 Trent Hepatitis C Study Group assessment and management protocol (up to 1998). HCV, hepatitis $C$ virus; LFTs, liver function tests; PCR, polymerase chain reaction.

performed using Epi-Info 6.04b. Confidence interval (CI) analysis for $95 \%$ CI of proportions, Mann-Whitney, and logistic regression analyses were performed using SPSS for Windows $\mathrm{v} 8$.

\section{Results}

DEMOGRAPHY OF HCV ANTIBODY POSITIVE

PATIENTS IN THE TRENT REGION

The total number of anti-HCV positive patients recorded in Trent between 1 September 1991 and 1 December 1998 was 2546.

With an assumed total population of 5.12 million, this equates to an overall prevalence of known HCV antibody positivity of $0.05 \%$. The source of referral for antibody positive patients was hospital consultants for 1836 (72\%), 619 of whom were from genitourinary medicine clinics, general practitioners for 298 (11.7\%), and others (for example, NBA, haemophilia service) for $412(16.1 \%)$.

TRENT HEPATITIS C COHORT STUDY

Of the 2546 antibody positive patients in Trent, 218 with haemophilia, 94 known to be coinfected with HIV, and 185 on renal dialysis were not included in the Trent cohort study. Of the remaining 2049 patients, 921 have not attended an outpatient appointment at one of the participating clinics; 1128 patients have attended at least one hospital outpatient clinic and form the Trent cohort described below. The known age and sex distributions of HCV infected patients are shown in table 1 . The male to female ratio was $2: 1$ in both groups. Mean duration of follow up of patients in the cohort was three years seven months (interquartile range two years five months to five years four months). 
Table 1 Date of birth and sex distribution of anti-hepatitis $C$ virus (HCV) positive patients

\begin{tabular}{lcc}
\hline $\begin{array}{l}\text { Decade of } \\
\text { birth }\end{array}$ & $\begin{array}{l}\text { All anti-HCV positives } \\
(\text { No }(\%))(n=2310)\end{array}$ & $\begin{array}{l}\text { Trent HCV study group } \\
(\text { No }(\%))(n=1122)\end{array}$ \\
\hline $1910-19$ & $28(1.2)$ & $13(1.2)$ \\
$1920-29$ & $91(3.9)$ & $38(3.4)$ \\
$1930-39$ & $93(4.0)$ & $40(3.6)$ \\
$1940-49$ & $165(7.1)$ & $85(7.6)$ \\
$1950-59$ & $519(22.5)$ & $350(31.2)$ \\
$1960-69$ & $884(38.3)$ & $171(5.2)$ \\
$1970-79$ & $450(19.5)$ & $9(0.8)$ \\
$1980-89$ & $25(1.1)$ & $1(0.1)$ \\
$1990-99$ & $55(2.4)$ & Trent HCV study group \\
Sex & All anti-HCV positives & $($ No $(\%))(n=1122)$ \\
& No (\%)) (n=1987)t & $763(68)$ \\
\hline Males & $1443(73)$ & $364(32)$ \\
Females & $544(27)$ &
\end{tabular}

Relatively $27 \%$ more males in all $\mathrm{HCV}$ positives $(8-49 \%$, $\mathrm{p}=0.004)$.

†Data incomplete due to sex not reported by one laboratory.

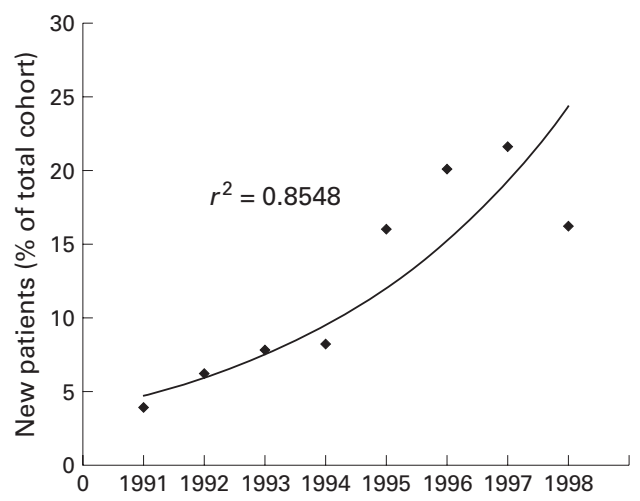

Figure 2 Percentage of new referrals on a yearly basis during the study period, 1991-1998.

The number of patients referred to the cohort has increased annually by $23.4 \%$ during the period of study, as shown in fig 2 . The pattern of referral has changed with time-for example, the NBA referral rate has reduced from $50 \%$ of new patients in 1991-1993 to 2\% in 1997.

Ethnic origin data were collected from 704 cohort patients (62\%): $95 \%$ were Caucasian. Data from the epidemiological questionnaire were available from 719 cohort patients (70\%). Risk factors, expressed as a hierarchy whereby an individual patient is classified according to the highest level of risk, are shown in table 2 (order shown in table). Forty per cent of patients admitted to more than one risk factor.

Sera from 695 of $860(81 \%)$ patients tested by qualitative RT-PCR were positive for $\mathrm{HCV}$ RNA; sera from the remaining 165 (19\%) patients were negative. PCR negativity rates were similar in those infected through IDU $(18.6 \%)$ and those infected through receipt of blood components (19.9\%). Over $90 \%$ of the known PCR positive patients in the cohort had at least two PCR tests. There were five instances of patients who were initially PCR positive who became PCR negative on follow up without intervening therapy. At least three of these patients were deemed clinically to have had acute HCV infection.

The genotype of the infecting HCV, tested in 304 patients, was $1(47 \%), 2(10 \%), 3(39 \%)$,
Table 2 Risk factors for hepatitis $C$ virus (HCV) infection among 719 patients in the cohort

\begin{tabular}{lc}
\hline Risk factor & No $(\%)(n=719)$ \\
\hline Intravenous drug abuse & $464(64.5)$ \\
Receipt of blood components & $132(18.4)$ \\
Non-professional tattoo & $17(2.4)$ \\
Sex with drug user & $9(1.3)$ \\
Health care worker & $12(1.7)$ \\
Born outside UK & $23(3.2)$ \\
Tattoos & $13(1.8)$ \\
Non-professional ear piercing & $3(0.4)$ \\
None of the above & $46(6.4)$ \\
\hline
\end{tabular}

$4(1 \%)$, and $5(2 \%)$. The distribution of genotypes was different in those patients whose primary risk factor was receipt of blood components compared with IDU, with a higher percentage of type 1 infection in the former $(60 \% v 47 \%)$ and of type 3 in the latter $(43 \% v$ $\left.21 \% ; \chi^{2}=8, d f s=2, p=0.02\right)$ (table 3 ).

Of 507 patients tested for markers of past (antibody to hepatitis B core antigen (anti$\mathrm{HBc})$ ) or present (hepatitis B surface antigen (HBsAg)) hepatitis B virus (HBV) infection, $185(36.5 \%)$ were anti-HBc positive and 18 (3.5\%) were HBsAg positive (two were also $\mathrm{HBeAg}$ positive).

LIVER BIOPSY DATA

Diagnostic liver biopsy was performed on 588 cohort patients, of whom 397 were scored (Knodell system) by the same pathologist (table 4): 157 (40\%) had a total Knodell score of 6 or greater. Of all patients who had liver biopsy, $8.3 \%$ had cirrhosis (fibrosis stage 4 ) at presentation.

An analysis was performed of factors which may impact on the development of fibrosis on the initial biopsy. Univariate analysis shown in fig 3 of the highest known weekly alcohol intake admitted to by each patient and fibrosis (stages 3 and 4) on biopsy demonstrated a strong association between the two factors $\left(\chi^{2}=48\right.$, $\left.\mathrm{df}=3, \mathrm{p}<10^{-8}\right)$. In all cases the highest known weekly alcohol intake was prior to the initial clinic assessment.

Multiple logistic regression analysis (backward regression, likelihood ratios) was performed examining variables associated with fibrosis as the dependent variable ( 0 or $1 v 3$ or 4). Variables included in the model were current age, sex, route of infection, genotype, alcohol (highest known weekly alcohol intake), hepatitis B status, age at infection and duration of infection, and necroinflammatory grade. This demonstrated an association between fibrosis stage 3 or 4 and evidence of exposure to hepatitis B (anti-HBc positive, regardless of the presence or absence of $\mathrm{HbsAg}$ ), age at the time of biopsy, and necroinflammatory grade, as shown in table 5 . There was no independent association with sex, genotype, alcohol intake, estimated duration of infection, or route of infection. Older patients were more likely to have a history of higher alcohol consumption $(p=0.03)$ which may have influenced the results of the statistical model. However, the statistical model did not show alcohol as an independent variant.

A total of 153 patients (26\% of those who had undergone liver biopsy) were treated with 
Table 3 Hepatitis $C$ virus (HCV) genotype in 304 patients in the Trent cohort

\begin{tabular}{lccl}
\hline Genotype & $\begin{array}{l}\text { No patients (\%) } \\
(n=304)\end{array}$ & $\begin{array}{l}\text { Infection from blood } \\
\text { components } \\
(\text { No }(\%))(n=47)\end{array}$ & $\begin{array}{l}\text { Infection from intravenous } \\
\text { drug use } \\
\text { (No (\%)) }(n=149)\end{array}$ \\
\hline 1 & $143(47)$ & $28(59.6)$ & $70(47)$ \\
2 & $31(10.2)$ & $4(8.5)$ & $13(8.7)$ \\
3 & $120(39.4)$ & $10(21.1)$ & $64(42.9)$ \\
4 & $3(1)$ & $0(0)$ & $1(0.7)$ \\
5 & $7(2.3)$ & $5(10.6)$ & $1(0.7)$ \\
\hline
\end{tabular}

Table 4 Knodell scores on 397 initial liver biopsies

\begin{tabular}{lrrrrr}
\hline & \multicolumn{3}{c}{ Fibrosis stage } & \\
\cline { 2 - 4 } NI grade & \multicolumn{1}{c}{1} & \multicolumn{1}{c}{ Total } \\
\hline Minimal (0-3) & 151 & 27 & 5 & 3 & 186 \\
Mild (4-8) & 48 & 84 & 23 & 17 & 172 \\
Moderate (9-13) & 1 & 11 & 13 & 11 & 36 \\
Severe (14-18) & 0 & 0 & 1 & 2 & 3 \\
Total & 200 & 122 & 42 & 33 & 397 \\
\hline
\end{tabular}

NI, necroinflammatory.

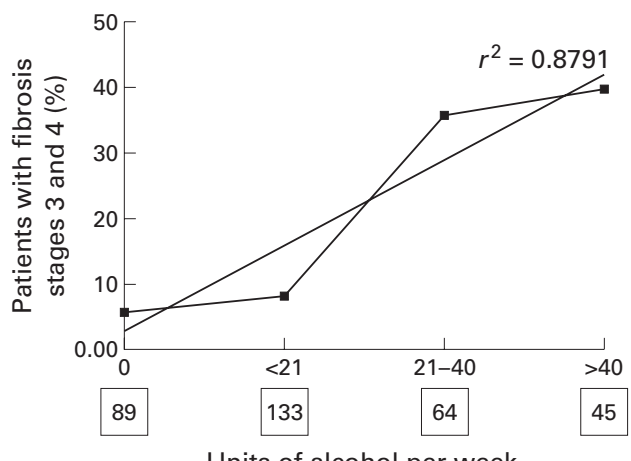

Units of alcohol per week

Figure 3 Highest known alcohol consumption in relation to hepatic fibrosis grades 3 and 4 in 331 patients with hepatitis $C$ (numbers in boxes represent number of patients).

Table 5 Multivariate analysis of predictors of fibrosis stages 3 and 4 at initial biopsy

\begin{tabular}{lll}
\hline Factor & Odds ratio & $95 \%$ CI \\
\hline $\begin{array}{l}\text { Age at biopsy (y) } \\
\quad<30\end{array}$ & Ref & \\
$30-39$ & 11.1 & $1.2-106$ \\
$40-49$ & 23.2 & $2.4-224$ \\
$\quad>50$ & 131 & $11.7-1483$ \\
Hepatitis B markers & & \\
$\quad$ Anti-HBc neg & Ref & \\
Anti-HBc pos & 3.4 & $1.0-11.1$ \\
NI grade & & \\
$0-4$ & Ref & \\
$5-8$ & 7.6 & $2.9-20$ \\
$9-12$ & 43 & $10.3-184$ \\
$13-18$ & 82 & $2.4-2770$
\end{tabular}

NI, necroinflammatory; anti-HBc, antibody to hepatitis B core antigen.

interferon. Thirty one patients (20\%) had treatment withdrawn or the dose reduced because of side effects, 45 patients $(29 \%)$ had an initial virological response (PCR negative at or up to three months), but 33 relapsed after cessation of therapy. Twelve patients remained HCV PCR negative six months after treatment, a sustained response rate of $7.8 \%$.

MORTALITY AND MORBIDITY

Sixty six patients from the cohort are known to have died. Mean age at death and the underlying causes of death, as indicated on the death
Table 6 Category of death grouped by ONS main cause of certified death, with mean age and sex ratio

\begin{tabular}{lccl}
\hline Category of death & Total & $\begin{array}{l}\text { Sex ratio } \\
(M: F)\end{array}$ & $\begin{array}{l}\text { Mean age } \\
(y)\end{array}$ \\
\hline Not yet ascertained & 8 & $6: 2$ & 48.3 \\
Lifestyle related & 12 & $10: 1$ & 33.0 \\
Liver & 24 & $17: 7$ & 51.8 \\
Related liver & 7 & $5: 2$ & 42.4 \\
Unrelated medical & 15 & $14: 1$ & 56.1 \\
Total & 66 & $52: 14$ & 48.2 \\
\hline
\end{tabular}

${ }^{\star}$ Suicide, drug overdose, and murder; ${ }^{\star \star}$ underlying liver disease stated as a contributory cause of death; ${ }^{\star \star \star}$ includes cancer, coronary heart disease.

certificate, are shown in table 6. Hepatocellular carcinoma was diagnosed in 12 patients. Liver transplantation was undertaken in five patients (one with HCC and four for end stage liver disease).

The expected number of deaths for patients with the age and sex structure of the Trent cohort, calculated using age and sex specific death rates (Office of National Statistics), is 13.5 for males and 5.5 for females. In our cohort there were 52 male deaths and 14 female deaths (table 6). Therefore, there was a relative increase in deaths of 3.9-fold for males (95\% CI 3.3-4.4) and 2.5-fold for females (95\% CI 1.1-3.9). There have been four deaths (all male: two liver related, one suicide, one respiratory failure) among those members of the cohort whose HCV infection was discovered as a result of them presenting as blood donors. Using the same methodology as above, the relative increase in deaths in this subgroup is 1.7 -fold for males and 0.5 -fold for females (ns). The "unrelated medical" deaths were similar to the expected number of deaths for patients with the age and sex structure of the Trent cohort - the excess was related to "liver", "liver related", and "lifestyle" deaths.

\section{Discussion}

Published prevalence data for hepatitis C infection in the UK vary from $0.08 \%$ to $0.72 \%$ and are mainly derived from selected populations such as organ donors, tertiary referral centres, blood donors, and antenatal clinics. ${ }^{6-8}$ We established a multidisciplinary region wide research group to study the epidemiology and natural history of hepatitis $\mathrm{C}$ in a large population in the UK of 5.12 million. Trent region does not contain a tertiary referral centre for patients with advanced liver disease and thus our data are not biased by over representation of this patient group. We have noted a progressive rise in newly diagnosed $\mathrm{HCV}$ infected patients referred to the cohort $(23.4 \%$ annually). The study cohort consisted of those referred to one of the participating centres and amounted to $44 \%$ of all known HCV positive patients in the region. In accordance with other studies, most patients with $\mathrm{HCV}$ antibodies were also HCV RNA positive. There were no identified epidemiological characteristics among the $19 \%$ who were PCR negative.

The sex ratio of 2:1 (male:female) was the same in the cohort and the known positives in the region but is in striking contrast with a 
reported ratio of $1: 1$ from one USA community based study. ${ }^{18}$ The distribution of dates of birth differed slightly between all known positives and the cohort patients, with an increase in patients born in the 1950s in the latter group and in subsequent decades in the former group (table 1). We found that $\mathrm{HCV}$ infection was most common among young adults, over half of whom had been born in the 1960 s or later, which is consistent with previous observations. ${ }^{19}$ This age distribution and male:female ratio reflect the sociological characteristics of current injecting drug users. ${ }^{20}$ Current or past IDU was the most common risk factor for infection which was present in $65 \%$ of the cohort, a value higher than in other cohort studies. ${ }^{182122}$ This may reflect our selection bias, with exclusion of haemophiliacs, known HIV infected individuals, and patients receiving renal support. Educational initiatives to reduce risk as a means of preventing transmission of infection in the drug using community are clearly desirable although recent experience in Glasgow suggests this may be more difficult to achieve than with HIV. ${ }^{23}$

The second major risk factor $(18 \%)$ in the Trent cohort was receipt of blood components. The proportion of patients falling into this category has declined with time and the current risk of acquiring HCV infection through transfusion of blood components or products is now very small, although not absent. ${ }^{24}$

Data on source of infection (table 2) are presented as a hierarchy of risks whereby only one risk factor appears for each patient even though $40 \%$ admitted to more than one risk. We found that the number of patients who completed the epidemiological questionnaire but admitted to no identifiable risk factor for $\mathrm{HCV}$ infection was low $(6.4 \%)$; this contrasts with previously reported values which have exceeded $12 \%{ }^{25}$ and may reflect the detailed nature of the questionnaire and its completion assisted by experienced personnel. Some individuals may not admit to having engaged, perhaps transiently, in drug or needle related activities early in life-recall of unpleasant memories is notoriously selective ${ }^{26}$ and this may be relevant in some of the "no risk" group.

Genotype 1 is the most common type in Western countries with values of $63-72 \%$ reported. ${ }^{1027}$ Although it was the most common genotype in the Trent cohort, it accounted for only $47 \%$ of infections. A significant correlation between genotype 3 and infection by IDU compared with blood components was noted. This has been observed previously ${ }^{28}$ but not in every study. ${ }^{29}$

Of 397 initial liver biopsies scored by a single observer, established cirrhosis was evident in $8.3 \%$. Other studies have reported higher values of $17-59 \%,,^{10} 11222530$ a discrepancy which may relate to the unselected nature of the Trent cohort compared with data derived from patients attending tertiary referral centres. One of the important clinical issues in the management of HCV infection is to identify risk factors for progression to chronic liver disease. The present univariate analysis accords with others ${ }^{31}$ in that a higher level of admitted alcohol intake is associated with advanced liver fibrosis.

Multivariate analysis of risk factors demonstrated a strong correlation between fibrosis and age at biopsy, with patients over 50 years having a 131-fold increased risk of fibrosis stage 3 or 4 compared with patients aged less than 30 years (95\% CI 4.4-253). This may reflect a longer duration of infection (although estimated duration of infection was not identified as an independent risk factor, it was not definable in all cases), different host response with age, longer exposure to alcohol ingestion, or other factors. This strong association with age may explain the absence of alcohol as an independent factor from the final multivariate models.

An unexpected finding was that serological evidence of past infection with HBV was also associated with an increased risk (relative risk $3.4,95 \%$ CI $1.0-11.1$ ) of the biopsy showing fibrosis stage 3 or 4 . This was not due to interaction between past HBV infection and level of alcohol consumption. An association with past HBV infection (that is, anti-HBc positive, HBsAg negative) has not previously been reported to our knowledge, although "serologically silent" or "occult" HBV infection (HBV DNA positive, HBsAg negative, anti-HBc positive or negative) has been linked with increased histological severity scores in chronic HCV infection. ${ }^{32}$ This observation has important clinical implications, particularly with respect to reinforcing efforts to deliver hepatitis $\mathrm{B}$ immunisation to those at risk of acquiring $\mathrm{HCV}$ infection, especially in the drug injecting population. A higher necroinflammatory grade was also an independent factor related to degree of fibrosis, which in turn is likely to reflect disease activity and level of fibrin production. No other independent associations were noted, particularly with regard to sex, genotype, route of infection, alcohol intake, and duration of infection.

Intervention in our cohort is currently targeted at patients with a total Knodell score of $\geqslant 6$. However, in our experience interferon monotherapy yielded a sustained response rate of only $7.8 \%$, which is lower than reported rates of $15-20 \% .^{33} 34$ This discrepancy may have arisen because of different methods of patient selection, use of regimens subsequently shown to be suboptimal (for example, six month courses), and different compliance rates among clinical trial patients compared with unselected patients attending hospital clinics. It does, however, give a real community response value for interferon therapy up to 1998 in a large cohort and emphasises that results from clinical trials may not translate directly to the routine clinic setting. Combination therapy with interferon and ribavirin has now replaced interferon monotherapy as standard treatment. $^{27} 35$

The occurrence of 66 deaths seems surprisingly high for a relatively young cohort of patients. The unrelated medical deaths showed no increase over the expected number. The "liver" and "liver related" deaths were responsible for $47 \%$ of all deaths in this cohort which 
is higher than that observed in studies by Seef et al who found a liver related death rate in transfusion acquired $\mathrm{HCV}$ infection of only $3.3 \%$ but patients in that study were older and, by definition, suffering from other pathologies which may have contributed to their deaths. ${ }^{36}$ The high number of "lifestyle deaths" presumably relates to the drug related lifestyle of such patients who, in one study, were 22 times more likely to die a premature death compared with an equivalent general population. ${ }^{37}$ Despite the small number of deaths within the blood donors in this cohort, there was an excess of male deaths in this subgroup which is compatible with the hypothesis that the increase in male deaths in the whole cohort represents a real risk.

Thus far hepatocellular carcinoma has been diagnosed in 12 cohort patients, and five liver transplants have been performed. The health economic costs of managing $\mathrm{HCV}$ infection are the subject of a separate study.

In conclusion, $\mathrm{HCV}$ infection is an emerging health problem in the Trent region. The clearer recognition of risk factors for infection and factors associated with progressive disease will enhance our understanding of hepatitis $\mathrm{C}$ and facilitate better targeting of therapeutic interventions. An excess mortality in infected individuals is already evident in this cohort. This regional cohort has provided the opportunity to study the natural history of hepatitis C in a large population and further research into aspects of the sociology, health economics, pathogenesis, virology, and therapy of this very important infectious disease is underway.

\section{Appendix}

CONTRIBUTORS

The Trent HCV cohort study was planned and designed by Virge James, Will Irving, Keith Neal, Bing Jones, Roger Finch, David Triger (deceased), Michael McKendrick, Jan Freeman, Brian Scott, Karl Nicholson, and Martin Wiselka. The risk factor questionnaire was designed by Keith Neal and Bing Jones. Genome amplification assays were performed by Will Irving and Goura Kudesia. All liver biopsies were assessed and scored by James Underwood. Patients were examined and cared for by Jan Freeman (Derby), Karl Nicholson and Martin Wiselka (Leicester), Brian Scott (Lincoln), Roger Finch, Steve Ryder, and Brian Thomson (Nottingham), Dermot Gleeson, Stephen T Green, Michael McKendrick, Abdul Mohsen, Robert Read, and Matthias Schmid (Sheffield). Mandy Holliday, Maggie Nicholls, Yvonne Dawes, and Julie James are research nurses responsible for recruitment and long term follow up of patients, administration of the questionnaire, and maintenance of the database. The paper was written by the writing committee, and reviewed and agreed by all members of the Trent HCV Study Group.

WRITING COMMITTEE (IN ALPHABETICAL ORDER)

ST Green, WL Irving, DA Jones, MW McKendrick, A Mohsen, KR Neal, SD Ryder.

THE TRENT HCV STUDY GROUP (NUMBERS IN PARENTHESES INDICATE CURRENT NUMBERS OF PATIENTS CONTRIBUTED TO THE COHORT ATTENDING EACH CLINIC)

Derby City Hospital, Derby, UK (gastroenterology, 113), J Freeman FRCP; Leicester Royal Infirmary, Leicester, UK (infectious diseases, 170), J James SRN, KG Nicholson FRCP, MJ Wiselka FRCP; Lincoln County Hospital, Lincoln, UK (gastroenterology, 91), BB Scott FRCP; National
Blood Authority, Trent Centre, UK, V James FRCPath, DA Jones MB, ChB (secretary of group); Nottingham City Hospital, Nottingham, UK (infectious diseases, 185), RG Finch FRCP, A Holliday SRN, BJ Thomson MRCP; Queen's Medical Centre, Nottingham, UK (medicine, 221), M Nicholls SRN, SD Ryder DM (microbiology), WL Irving FRCPath (chair of group), (public health medicine and epidemiology), KR Neal MFPHM; Royal Hallamshire Hospital, Sheffield, UK (infectious diseases, 380), Y Dawes SRN, ST Green MD, MW McKendrick FRCP, A Mohsen MRCP, RC Read FRCP, M Schmid MRCP (medicine 141), D Gleeson FRCP (virology), J Bremner MRCPath, G Kudesia FRCPath, (pathology), JCE Underwood FRCPath. The Trent Hepatitis C Study Group has received research
funding from the Department of Health, the National Blood funding from the Department of Health, the National Blood
Authority, and Roche Pharmaceuticals. RFLP genotyping was Authority, and Roche Pharmaceuticals. RFLP genotyping was
performed by Dr Chong-Gee Teo, Central Public Health Laboperformed by Dr Chong-Gee Te,
ratory, Colindale, London, UK.

This work was undertaken by AH Mohsen and Trent HCV Study Group who received funding from the Department of Health; the views expressed in this publication are those of the authors and not necessarily those of the Department of Health.

1 Choo Q-L, Kuo G, Weiner AJ, et al. Isolation of a cDNA clone derived from blood-borne non-A, non-B viral hepatitis genome. Science 1989;244:359-62.

2 Alter MJ. Epidemiology of hepatitis C in the West. Semin Liver Dis 1995;15:5-13.

3 Feinman SV, Berris B, Bojraski S. Post-transfusion hepatitis in Toronto, Canada. Gastroenterology 1988;95:464-9.

4 WHO. Hepatitis C: Global Update. Wkly Epidemiol Rec 1997;72:341-4.

5 Darwish MA, Faris R, Clemens JD, et al. High seroprevalence of hepatitis A, B, C and E virus in residents in an Egyptian village in the Nile Delta. Am $\mathcal{F}$ Trop Med Hyg 1996;54:554-8.

6 National Blood Service Infection Surveillance. London: National Blood Service Infection
PHLS-CDSC, 1998: report No 8.

7 Boxall E, Skidmore S, Evans C, et al. The prevalence of hepatitis B and C in an antenatal population of various ethhepatitis B and C in an antenatal population of

8 Wreghitt TG, Gray JJ, Allain JP, et al. Transmission of hepatitis $C$ virus by organ transplantation in the United Kingdom. F Hepatol 1994;20:768-72.

9 Gish GR, Lau JYN. Hepatitis C virus: eight years old. Viral Hepat Rev 1997;3:17-37.

10 Poynard T, Bedossa P, Opolon P, for the OBSVIRC, METAVIR, CLINIVIR and DOSVIRC groups. Natural history of liver fibrosis progression in patients with chronic hepatitis C. Lancet 1997;349:825-32.

11 Tong MJ, el-Farra NS, Reikes AR, et al. Clinical outcomes after transfusion-associated hepatitis C. N Engl $\mathcal{F}$ Med 1995;332:1463-6.

12 El-Serag H B, Mason AC. Rising incidence of hepatocellular carcinoma in the United States. $N$ Engl $₹$ Med 1999;340:745-50.

13 Detre KM, Belle SH, Lombardero M. Liver transplantation for chronic viral hepatitis. Viral Hepat Rev 1997;2:219-28.

14 Irving WL, Neal KR, Underwood JCE, et al. Chronic hepatitis in UK blood donors infected with hepatitis $\mathrm{C}$ virus. BMF 1994;308:695-6.

15 Harris KA, Gilham C, Mortimer PP, et al. The most prevalent HCVgenotypes in England and Wales are 3a and 1a. $f$ Med Virol 1999;58:127-31.

16 Neal KR, Jones DA, Killey D, et al. Risk factors for hepatitis $\mathrm{C}$ virus infection. A case-control study of blood donors in the Trent region (UK). Epidemiol Infect 1994;112:595-601.

17 Knodell RG, Ishak KG, Black WC, et al. Formulation and application of a numerical scoring system for assessing histopathological activity in asymptomatic chronic active hepatitis. Hepatology 1981;1:431-5.

18 Alter MJ, Margolis HS, Krawczynski K, et al. The natural history of community-acquired hepatitis $\mathrm{C}$ in the United history of community-acquired hepatitis
States. N Engl F Med 1992;327:1899-905.

19 Centres for Disease Control. Hepatitis surveillance report. Atlanta: CDC, 1994;55.

20 Frischer M, Leyland A, Cormack R, et al. Estimating the population prevalence of injection drug use and infection with human immunodeficiency virus among injecting drug users in Glasgow, Scotland. Am F Epidemiol 1993;138:19081.

21 Conry-Cantilena C, VanRaden M, Gibble J, et al. Routes of infection, viremia, and liver disease in blood donors found to have hepatitis C virus infection. N Engl F Med 1996;334: 1691-6.

22 Roudot-Thoraval F, Bastie A, Pawlotsky JM, et al. Epidemiological factors affecting the severity of hepatitis C virus-related liver disease: a French survey of 6,664 patients. The Study Group for the Prevalence and the Epidemiology of Hepatitis C Virus. Hepatology 1997;26:48590.

23 Goldberg DJ, Cameron S, McMenamin J. Hepatitis C virus antibody prevalence among injecting users in Glasgow has fallen but remains high. Commun Dis Public Health 1998;1: $95-7$. 
24 Schreiber GB, Busch MP, Kleinman SH, et al. The risk of transfusion-transmitted viral infection. N Engl f Med 1996; 334:1685-90.

25 Flamm SL, Parker RA, Chopra S. Risk factors associated with chronic hepatitis $\mathrm{C}$ virus infection: Limited frequency of unidentified source of transmission. Am $\mathcal{F}$ Gastroenterol 1998;93:597-600.

26 Bloom DE. Technology, experimentation, and the quality of survey data. Science 1998;260:847-8.

27 McHutchison JG, Gordon SC, Schiff ER, et al. Interferon alpha-2b alone or in combination with ribavirin as initial treatment for chronic hepatitis C. N Engl f Med 1998;339: 1485-92.

28 Bukh J, Miller RH, Purcell RH. Genetic heterogeneity of hepatitis C virus: quasi-species and genotypes. Semin Liver Dis 1995;15:41-63.

29 Serfaty L, Chazouilleres O, Poujol-Robert A, et al. Risk factors for cirrhosis in patients with chronic hepatitis $\mathrm{C}$ virus infection: results of case-control study. Hepatology 1997;26: infection:

30 Zein NN, Rakela J, Krawitt EL, et al. Hepatitis C in the United States: epidemiology, pathogenicity, and response to interferon therapy. Collaborative study group. Ann Intern Med 1997;125:634-9.
31 Wiley TE, McCarthy M, Breidi L, et al. Impact of alcohol on the histological and clinical progression of hepatitis C infection. Hepatology 1998;28:805-9.

32 Cacciola I, Pollicino T, Squadrito G, et al. Occult hepatitis B virus infection in patients with chronic hepatitis $\mathrm{C}$ liver disease. N Engl F Med 1999;341:22-6.

33 Poynard T, Leroy V, Cohard M, et al. Meta-analysis of interferon randomised trials in the treatment of viral hepatitis $\mathrm{C}$ : effect of dose and duration. Hepatology 1996:24:778-89.

34 Foster GR, Goldin RD, Main J, et al. Management of chronic hepatitis C: clinical audit of biopsy based management algorythm. BMF 1997;315:453-8.

35 Poynard T, Marcellin P, Lee SS, et al. Randomised trial of interferon alpha- $2 \mathrm{~b}$ plus ribavirin for 48 weeks or for 24 weeks versus interferon alpha- $2 \mathrm{~b}$ plus placebo for 48 weeks for treatment of chronic infection with hepatitis $\mathrm{C}$ virus. Lancet 1998;352:1426-32.

36 Seef LB, Buskell-Bales Z, Wright EC, et al. Long-term mortality after transfusion-associated non-A, non-B hepatitis. NEngl f Med 1992;327:1906-11.

37 Frischer M, Goldberg D, Rahman M, et al. Mortality and survival among a cohort of drug injectors in Glasgow, 1982-1994. Addiction 1997:92:419-27.

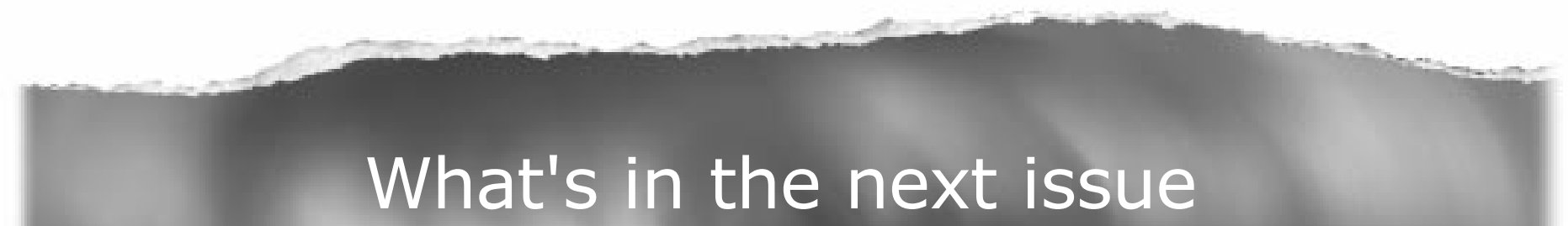

Future content

See which articles have just been accepted for publication and preview the table of contents for the next issue a month before it is published

www.gutjnl.com 